\title{
A Study of American Slangs in Billy Bathgate Translated by Yang Renjing from the Perspective of Translation Memetics
}

\author{
Chen Yanghan ${ }^{1, a}$, Zhuang Yajin ${ }^{2, b, *}$ \\ ${ }^{1}$ Foreign Languages College, Minnan University of Science and Technology, Shishi, Quanzhou City, \\ China \\ ${ }^{2}$ Foreign Languages College, Minnan University of Science and Technology, Shishi, Quanzhou City, \\ China \\ a997251010@qq.com,b854280789@qq.com
}

Keywords: literary translation, translation meme, Billy Bathgate, American slang, meme genotype, meme phenotype.

Abstract: The analysis and comparison to the translation of American slangs in Yang Renjing's translation of Billy Bathgate through the notions of translation memetics can deeply indicate the cultural nature behind American slangs, and further promote the exchange and communication of Chinese and foreign cultures with the conversion results of slang translation. By integrating the strategies adopted by the translator in the translation of slang memes to analyze the motivations and rules behind the transmission of American slangs, the discussions to the modes of spreading and developing slang memes in translation can be advanced. Also, the fact of cultural mutation and transformation in translation can be proved from the perspective of memetics to demonstrate the inevitability of the variation of American slang in communication due to the limitation of cultural differences.

\section{Introduction}

Under the background of globalization, translation plays an increasingly prominent role in specific fields as the staple means of cultural communication. Literary works crystallize the writers' subjective understanding and critical thinking. Studying foreign works can not only excavate the social forms and cultural trends of foreign countries in different periods, but also contribute to the cultural exchanges between China and foreign countries. In the 1970s, Dawkins first put forward memetics in his book The Selfish Gene, and scholars including Chesterman and Blackmore created a new theory of translation memetics by combining memetics with translation theory. By analyzing the translation and communication modes of American slangs in Yang Renjing's translation of Billy Bathgate through translation memetics, the features of slang memes' conversion and replication can be effectively drawn and moreover, the translation strategies of American slang memes in this novel can be summarized to provide supplementary and innovative ideas for future slang translation practice and expand the application of memetics in translation. Ultimately, it also hopes that 
translation activities will promote the mutual learning and strengthen cultural and people-to-people exchanges between China and foreign countries to enrich the wide spread of multiculturalism in the world.

\section{Translation meme and American slang in Billy Bathgate}

Translation memetics is an interdisciplinary mixture of memetics and translation theory, while slang reflects the connotation of a certain culture to some extent. The following mainly introduces the basic concepts, classifications and corresponding translation strategies of translation memetics, as well as illustrating the generation and development of American slangs.

\subsection{Translation Meme}

"Meme", is defined a unit of cultural transmission and imitation which arises in the need of conveying cultural communication and evolves gradually with mutation like gene inheritance. Memes will mutate during replication for the host's cultural background, personal wishes and other factors $^{[1]}$. Competition is the most essential feature of memes ${ }^{[2]}$, and they have to compete for better survival and spreading. He Ziran ${ }^{[3]}$ translates meme as “模因”, which spreads in human brains through imitation and replication, and it also exists in the external world in ample forms such as language, behavior, etc. ${ }^{[4]}$. Moreover, human brain is virtually the survival machine of memes designed by co-evolution of memes and genes, memes will react to the brain and have a slight influence on one's behavior as well ${ }^{[5]}$.

Translation meme is a concept introduced by Andrew Chesterman in his book Memes of Translation: The Spread of Ideas in Translation Theory. Language is the main aspect of cultural meme replication, it promotes cultural communication while accelerating the evolution of memes ${ }^{[6]}$. Memes spread in sundry cultures through imitation and language, so translation becomes a condition for the transmission of memes in other cultures. Chesterman ${ }^{[7]}$ puts forward another definition of translation: the human body is the survival machine of memes, and the translation is also the survival carrier of cross-cultural communication of memes. Memes are transmitted through language while language transmission needs to be realized through translation. Translation activities promote the spread of memes in time, space and culture, while translation itself actually is a meme ${ }^{[8]}$.

Translation meme is the extension and sublimation of memetics in translation field whose essential attribute and core connotation are almost equivalent to meme. The essential demand of memes is to transmit effectively. Perhaps some of memes can be copied widely with their strong vitality and connotation, or some may die at birth because of their inherent weaknesses and shortages $^{[9]}$. Memes can be divided into strong memes and weak memes according to their replication ability, in which the strong ones are successfully replicated and widely spread because of their superior contents and essences, while the weak ones often die out quickly for their own limitations ${ }^{[10]}$. The same is true of translation memes. Only those translation memes that have significance and values to translation activities will be applied and inherited.

He Ziran ${ }^{[11]}$ proposes two types of memes: meme genotype and meme phenotype. The former means that memes are copied in various forms with the same content whose information is directly replicated and transmitted. The latter refers to the replication forms of memes that do not change, but expand following different contents, and their information is endowed with diverse contents. There are numerous genotypes and phenotypes of memes in translation meme pool, which are divided according to the characteristics and commonness between translation and memes. Chesterman ${ }^{[7]}$ condenses the symbiotic features between memetics and translation strategies to draw conclusions as the following five supermemes in translation memes: source-target supermeme, 
equivalence supermeme, untranslatability supermeme, free-vs-literal supermeme and all-writing-is-translating supermeme.

Wang Lisong ${ }^{[10]}$ proposes two translation strategies of domestication and foreignization on the basis of the characteristics of strong and weak memes. For strong memes, they are rich in content and profound in connotation, so they can be widely spread and accepted by the host. Therefore, these strong memes can be copied as completely as possible in the target language through foreignization. Under the circumstance that weak memes are difficult to be widely copied and spread, translators can domesticate them into strong memes in the target language for the sake of readers' acceptance. He Ziran ${ }^{[11]}$ points out that meme phenotype is a kind of unequal replication and diffusion, which can be divided into translation meme variants such as free translation meme, amplification translation meme and omission translation meme. Zhao Shiqiang ${ }^{[12]}$ believes that literal translation and annotation are common methods for copying memes, which can retain the content, meaning and style of the original text to make the standard memes continue to spread as genotype variants.

\subsection{American slang in Billy Bathgate}

As a special language carrier with strong cultural connotation, American slang develops at a good pace and gradually becomes one of the crucial means for modern citizens' communication. Wang Niuniu ${ }^{[13]}$ proposes that slang initially had a low status, which was usually defined as "street language" and generally used by the lower class. But with the development of society, the meaning of American slang is constantly evolving. Yang Hui ${ }^{[14]}$ argues that slang is a life-oriented and colloquial folk statement with local color, informality and strong regionality used in casual situations. Slang is vitally bound up with national culture, customs and habits and acts with great regional differences. Liu Fangqiong ${ }^{[15]}$ considers that slang is a unique symbol of language and society from which cannot be separated. Besides, Zhu Hongying ${ }^{[16]}$ maintains that the whole American society is using slangs constantly which increases the creation of slang-related words and many vigorous slangs have already penetrated people's daily life, literature, movies, internet and other fields. The United States is a multi-ethnic country with various classes, and American slang clearly shows different gaps between cultures. Diversified cultures, social customs, people's attitudes and values of America are mirrored in American slangs.

The story of Billy Bathgate takes place in New York in the 1930s. Its core is to highlight ordinary people's awareness of organized crime and violence, and to expose the collusion and conflict between gangs and officials at that time, as well as persecution in the underworld and the plunder to innocent people. Hence, there are many violent and vulgar American slangs in this novel with only few gentle and polite slangs. Yuan Yuan ${ }^{[17]}$ believes that Doctorow accentuates the coexistence of people with different cultural backgrounds in New York by combining the triple identities of Jews, Americans and New Yorkers which expands the scope and vision of his novels. It can be discovered that noteworthy differences of social classes can be found in slangs of Billy Bathgate. Xu Zaizhong ${ }^{[18]}$ upholds that although Doctorow' s novels are full of concern and support for Jewish culture and socially vulnerable groups, he still advocates harmonious coexistence among diverse cultures and groups. Naturally, the American slangs used in Doctorow' s novels also reflect the great gaps among different social groups, which is of great academic value.

\section{Analysis of American slang's translation meme in Yang Renjing's translation}

Given the profound culture behind slangs, it is necessary to adopt specific strategies to solve the problems in slang translation. Wang Niuniu ${ }^{[13]}$ puts forward three principles of American slang 
translation: faithfulness, accuracy and unification. It is necessary for translators to follow translation strategies such as transliteration, free translation, literal translation and conversion to solve the un-translatability of the original text flexibly. Yang Hui ${ }^{[14]}$ proposes two methods: one is to translate slangs in the source language into the standard target language, and the second is to translate slang into expressions with weak semantics in the target language. In the following part, the source and the target texts will be comparatively analyzed via the translation strategies derived from meme genotype and phenotype in translation memetics.

\subsection{Meme genotype}

It is meaningful to combine meme genotype and phenotype with translation to analyze translation activities ${ }^{[20]}$. He Ziran argues that genotype is the equivalent transformation of original information between the source language and target language ${ }^{[3]}$. Chen Daoming ${ }^{[21]}$ holds that meme genotype spreads language forms and ways of thinking. Some scholars hold that genotype retains cultural connotation and content to a great extent ${ }^{[22]}$. Chen Xinren ${ }^{[23]}$ proposes that genotype is a typical transmission of memes with highly accurate imitation and replication. The three strategies of literal translation, transliteration and annotation in the translation are just in line with the characteristics of meme genotype.

\subsubsection{Literal translation in meme conversion}

To retain the content and form of the source text and correctly convey the original meaning as much as possible, translators will usually use literal translation. Literal translation properly matches the basic definition of meme genotype for the same goals of keeping the main idea of the source meme and therefore it is an appropriate option to analyze the translation under meme genotype.

Example 1:

Source text: “...Where did you two meet? How long you been lovebirds?”

Target text: “......你俩在哪里相遇的呢? 你们两只爱情鸟在一起多久了?”

The meme genotype in the pool of translation meme means the equivalent transmission of the original information between the source and target languages ${ }^{[11]}$. "Lovebird" in Example 1 means two people who deeply love each other, and in Chinese, there is a similar expression of "lovebirds" called “比翼鸟 (two inseparable birds)”. “Lovebirds” can be seen as a meme and “比翼鸟” actually is its equivalent meme in Chinese, and Yang translates it literally without any modification to completely transmit the original meaning of "lovebirds", which follows the mode of meme genotype's transmission and correctly achieves the equality of information of two memes between the source meme and the target meme. And this translation can not only preserve the exotic color of the source text, but also facilitate the target readers to understand the original meaning.

\subsubsection{Transliteration in meme conversion}

Transliteration aims to translate by finding words with similar pronunciation which is often used in translating human or place names and special sounds. People would find homologous words or create new words by restructuring letters to represent specific sounds called onomatopoeic words which are very common in spoken English and writing. Transliteration can convey the original meaning and form without destroying the features of the source text which correspondingly reflects the core of meme genotype as well.

Example 2:

Source text: ...smiling his vacuous uh-hums of encouragement...

Target text: ......停着没有内容的“鸣-恩”, 表示鼓励。 
The original content is the kernel in the process of spreading, copying and inheriting memes ${ }^{[24]}$. "Un-hums" is a sound that people will utter when they talk to others to express understanding, approval and hope that the speakers will continue their talk or give a positive answer. Yang Renjing translates “Un-hums” as “鸣-恩” because they have similar pronunciations, which constitutes a pair of counterparts in Chinese and English. “Un-hums” and “鸣-嗯” are the different forms of one meme genotype, and they exist with the same gene and indicate the same connotation but in dissimilar languages. “鸣-嗯” is the inner manifestation of the source meme in another facet while "Un-hums" is the natural noumenon of the target meme.

\subsubsection{Annotation in meme conversion}

Annotation is used at the bottom of the same page, namely footnote, or the end of the book, namely endnote, to explain certain concepts for avoiding doubts of readers. It is an explanatory text added based on literal translation with the function of retaining the source text's content and form under the demand of meme genotype like literal translation and transliteration.

Example 3:

Source text: ...not even if it is plus or minus, you call it X.

Target text: ...... 是正是负都不清楚, 你就叫它 $X^{(1)}$ 。

Annotation: (1)未知数

In English, apart from being a letter, “X” also means "an unknown number” which usually refers to something uncertain. In the process of transforming and deciphering memes of foreign cultures, translators play the dual roles of decoder and important transmitter of source memes ${ }^{[8]}$. “(1)未知数” is added to explain the true meaning " $\mathrm{X}$ " indicates, which can make target readers understand its genuine connotation better. “未知数” and “ $X$ ” are two different expression forms of memes, but their contents are completely consistent. Meme “未知数” appears as the form of an annotation, which is transformed into a more detailed meme of target language according to readers' needs, and fulfills the inheritance and mutation of source meme " $X$ " in gene's content.

\subsection{Meme phenotype}

He Ziran ${ }^{[3]}$ perceives that phenotype is the unequal replication and transformation of information from the source language to the target language. Chen Daoming ${ }^{[21]}$ believes that meme phenotype is spread in the same form, but expressed in different contents. Wang Lisong and his partners ${ }^{[22]}$ put forward that phenotype changes cultural intention with cultural content becoming rich, even completely different. Chen Xinren ${ }^{[23]}$ argues that phenotype is the external formation because it can be expressed in the same way, but its content and thought have been changed, thus breaking away from complete replication. It can be seen that meme phenotype is closely related to three translation strategies: free translation, amplification and omission.

\subsubsection{Free translation in meme conversion}

Free translation refers to translating the main idea of the source text, without maintaining the use of words, figure of speech and linguistic structure of the original. It is mainly applied when great cultural differences occur between two languages, which can effectively enhance the acceptability of translation. Free translation would inevitably change the original meanings and textual forms of the source text, which highly matches with meme phenotype' definition.

Example 4:

Source text: "Not exactly your salt of the earth." 
Target text: “他并不是你认为的高尚人士。”

In English, the slang "salt of the earth" means someone who is kind and honest. It is a little bit rigid and doesn't conform to the context if the translator directly translates this phrase into Chinese as “非常善良诚实的人”, so the four-character phrase “高尚人士” is a good option the translator adopt to promote the quality of translation and meets the expected vision of target readers. Meme phenotype in translation meme is the mode of information transformation from the source language to the target language, which is a kind of non-equivalent replication and diffusion ${ }^{[11]}$. Meme phenotype is spread via the mutation of the content of the source meme. In Example 8, under the premise of reserving part of the source meme's content, the translator translates it into a more appropriate target meme, even though both of them are not totally equivalent. However, the genetic content of the source meme is still conveyed unfailingly.

\subsubsection{Amplification in meme conversion}

Amplification means adding some words, phrases or sentences in translation according to the different language conventions and expressions between English and Chinese, and the context logic as well, so as to more accurately express the meaning contained in the source text but not actually appearing. Annotation is another major translation strategy in meme phenotype to transmit cultural memes by changing their original contents and forms.

Example 5:

Source text: ...to a punk to find easy money except one way, ...

Target text: ...... 给小流讯去捞不义之财的, ......

Language memes are often combined with diverse contexts in copying and spreading, which creates new connotations and components to form new meme complexes ${ }^{[11]}$. "Easy money" in American slang means the money made with little effort and raised easily. In Example 9, Yang translates “easy money” as “不义之财 (dirty money)”, replenishing “不义” to show the money made dishonestly which flexibly connects with the background in the former context. As the corresponding meme of “easy money” in Chinese, “不义之财” highlights the connotation of the source meme, and the translator changes the content of the target meme by adding the hidden points in the gene of the source meme, which makes the target meme “不义之财” thoroughly explained and completes the transmission of meme phenotype.

\subsubsection{Omission in meme conversion}

Omission refers to deleting words that do not conform to the language conventions and expressions of the target language and redundant words without actual meanings in the content to avoid the cumbersome translation.

Example 6:

Source text: "That is a laugh and a half."

Target text: “这话真好笑。”

All the memes in the pool of translation meme will replicate the old ones, but the final results of their transmission may have some changes like the amplification and omission on their original contents $^{[8]}$. In American slang, “a laugh and a half” means something interesting and funny or the laughing stock of somebody. This slang can be translated directly into Chinese as “引人发笑的事” or “笑柄”, but Yang just translates it as an adjective “好笑 (funny)”, omitting the redundant element “...的事” which simplifies the translation. The omission of the target meme provides a more flexible and smoother replication and spread for the source one. Meme phenotype stresses that memes can transmit effectively without being constrained by the original content itself. 


\section{Conclusion}

The above analysis starts with the translation of American slang to find the cultural and emotional colors of slang memes transmitted among different hosts, which further verifies the nature of mutation and transformation of memes as the basic units of cultural communication. In the meanwhile, it confirms the inevitable law that translation originates from memes and sublimates memes, and explains the translation strategies and principles inherent in translation memetics. This analysis expounds two situations in which meme genotype and phenotype alter the content and form of cultural information in translation, and decodes the action modes of meme genotype and phenotype. Finally, by dissecting the translation of literary works, we can effectively explore the cultural images and loads contained therein, and promote the better transmission and exchange of a country's culture internationally.

\section{References}

[1] Dawkins, R. The Selfish Gene[M]. Oxford: Oxford University Press, 1976: 163, 172.

[2] Distin, K. The Selfish Meme[M]. Cambridge: Cambridge University Press, 2005: 185.

[3] He Ziran. New Developments in Pragmatics: Relevance, Adaption and Memetics[M]. Shanghai: Shanghai Educational Publishing House, 2007: 165.

[4] Feng Jianming, Mo Aiping. Ontology, Epistemology and Axiology---Memetics and Cultural Evolution[J]. Journal of Foreign Language, 2019 (2): 54-61.

[5] Aunger, R. Darwinizing Culture: The Status of Memetics as a Science[M]. Oxford: Oxford University Press, 2000.

[6] Brodie, R. Virus of Mind: The New Science of Meme[M]. New York: Integral Press, 1996.

[7] Chesterman, A. Meme of Translation: The Spread of Ideas in Translation Theory[M]. Amsterdam: John Benjamins Publishing Co., 1997: 7.

[8] Wang Xueyu. An Analysis of Translation Memetics[J]. Journey of Fuzhou University, 2010 (1): 74-78.

[9] Blackmore, S. The Meme Machine[M]. Oxford: Oxford University Press, 1999.

[10] Wang Lisong. Analyzing Alienation and Domestication Based on Strong Meme and Weak Meme[J]. Journal of Tianjin University, 2013 (4): 350-353.

[11] He Ziran. Meme in Language[J]. Linguistic Sciences, 2005 (6): 54-64.

[12] Zhao Shiqiang. A Chinese Translation Practice Report of the Rose Garden(Excerpt) from the Perspective of Translation Memetics[D]. Dalian: Dalian Ocean University, 2019: 6-18.

[13] Wang Niuniu. An Analysis of American Slang Translation[J]. Journal of Shanxi Normal University, 2010 (37): 87-89.

[14] Yang Hui. Violence of Translation: A Case Study of Subtitle Translation of Slangs in The Godfather Series[J]. Journal of Lanzhou Jiaotong University, 2018 (6): 131-137.

[15] Liu Fangqiong. A Study on the Regional Differences Between British and American Slang[J]. Journal of Guangxi University for Nationalities, 2020 (4): 200-204.

[16] Zhu Hongying. Linguistic Features of Slangs about Money and Its Social Culture Cognition[J]. Journal of Qiqihar University, 2019 (11): 114-117.

[17] Yuan Yuan. On the Cultural Implication of E. L. Doctorow's New York Writing[J]. Journal of Central South University, 2016 (2): 181-185.

[18] Xu Zaizhong. Race, Gender and Class: An Exploration of E. L. Doctorow's Compromising Politics in Ragtime[J]. Foreign Literatures, 2019 (3): 125-135.

[19] Liu Wenxia, Li Songying. Translation Memes in Evolution[J] Shanghai Journal of Translation, 2020 (5): 48-52.

[20] Chen Daoming. Cognitive Study of Meme and Meme Phenotype[J]. Journal of Xi'an International Studies University, 2013 (1): 46-49.

[21] Wang Lisong, Ge Liying, Zhao He, Lu Wanchen. Study on Eco-Translatology Through Analyzing Memes of Translation and Translation as Adaption and Selection[J]. Journal of Tianjin University, 2014 (4): 349-353.

[22] Chen Xinren. A Linguistic Memetics Interpretation of Lexical-Grammatical Innovation[J]. Foreign Language Education, 2017 (3): 12-16.

[23] Liu Huiyun. Translation Strategy Memes and Translation Practice[D]. Lanzhou: Lanzhou University, 2016: 20-50. 